\title{
Second and Third Virial Coefficients for Hydrogen
}

\author{
R. D. Goodwin, D. E. Diller, H. M. Roder, and L. A. Weber \\ Cryogenic Engineering Laboratory, National Bureau of Standards, Boulder, Colo.
}

(August 15, 1963)

\begin{abstract}
Second and third virial coefficients for parahydrogen have been derived from closely spaced PVT data from 24 to $100{ }^{\circ} \mathrm{K}$. They are in good agreement at $100{ }^{\circ} \mathrm{K}$ with published data for normal hydrogen. Analytical representations of the combined data from about 20 to $423^{\circ} \mathrm{K}$ are presented which may be useful in computation of thermodynamic functions of the gas. These formulas are related to those resulting from the use of the Lennard-Jones potential.
\end{abstract}

\section{Introduction}

As part of an extensive program for determining the thermodynamic and transport properties of fluid parahydrogen, we have recently published new data on the $\mathrm{P}-\mathrm{V}-\mathrm{T}$ surface from 15 to $100{ }^{\circ} \mathrm{K}$ [1]. ${ }^{1}$ Earlier, we gave preliminary values of the second and third virial coefficients, $B(T)$ and $C(T)$, in a paper describing the apparatus [2].

In this paper we present final values of the virial coefficients derived from the smoothed compressibility data [1]. These differ but slightly from the preliminary values. Also we present and examine analytical representations of $B(T)$ and $C(T)$ which may be useful for computing thermodynamic functions of the gas.

In a forthcoming paper [3] we have used the following arbitrary representations [4] to fit our closely spaced data in order to facilitate computations of thermofunctions below $100{ }^{\circ} \mathrm{K}$ :

$$
B=\sum_{i=0}^{3} b_{i} T^{-i} ; \quad C=\sum_{i=1}^{4} c_{i} T^{-i} .
$$

On the other hand, in this paper use is made of other published virial coefficients as well as those from this laboratory to provide a more extensive tabulation from about 20 to $423{ }^{\circ} \mathrm{K}$ to which are fitted expressions having forms suggested by the use of the Lennard-Jones potential. All coefficients were determined by the method of least squares.

\section{Derivation of the Virial Coefficients}

The virial expansion [5] may be rearranged to a form which, when truncated, is linear in density on isotherms, convenient for graphical or analytical de-

\footnotetext{
1 Figures in brackets indicate the literature references at the end of this paper.
}

termination of the second and third coefficients,

$$
\Phi \equiv(P v-R T) v=R T B+R T C / v+\ldots .
$$

Parameters RTB and RTC of eq (1) as truncated have been determined on isotherms by least-squares using the reported compressibility data [1] and the orthobaric densities [6]. The number of datum pairs, $n$, on each isotherm is given in column (a) of table 1. It was found by trial that data for densities above $0.007 \mathrm{~g} \mathrm{~mol} / \mathrm{cm}^{3}$ diverge from the linear behavior of eq (1). These data were omitted, with the result that a maximum of eight points per isotherm were applicable above $29^{\circ} \mathrm{K}$. (The above maximum density for validity of eq (1) with only two terms is less than half the critical density of $0.0156 \mathrm{~g} \mathrm{~mol} / \mathrm{cm}^{3}$ [6].) Derived values of $B$ and $C$ are given in tables 2 and 3 , respectively, at integral temperatures from 24 through $100{ }^{\circ} \mathrm{K}$.

Equation (1) also was used for smoothing and interpolation of compressibility data to the highest densities by admitting as many terms as required by the experimental precision [1]. At temperatures below critical $\left(32.98^{\circ} \mathrm{K}\right)$, a single isotherm of eq (1) was used to represent both vapor and compressed liquid. The number of datum pairs, $n^{\prime}$, and number of terms, $N$, in polynomial (1) are given in column (b) of table 1 which includes also the maximum density multiplied by $10^{3}$ for each isotherm. With increasing number of terms, the mean deviation decreases more at an odd number than at an even number of terms. Since coefficients of the higher-order terms of these divergent, alternating polynomials show no regular temperature-dependence, the expansions cannot be interpreted as virial equations [7]. Nevertheless, values of $B$ and $C$ obtained in this way are presented in appendix, table 1 , to meet the commonplace question of the effect upon them of an increased number of terms in eq (1). It may be seen that values of $B$ are essentially the same as in table 2. Values of $C$, while of similar magnitude to those in table 3, scatter badly. 
TABLE 1. Number of datum pairs, n, and of terms $\mathrm{N}$, for eq (1)

\begin{tabular}{|c|c|c|c|c|c|c|c|c|c|}
\hline \multirow{2}{*}{$T,{ }^{\circ} K$} & (a) & \multicolumn{3}{|c|}{ (b) } & \multirow{2}{*}{$T,{ }^{\circ} K$} & \multirow{2}{*}{$\frac{(\mathrm{a})}{n}$} & \multicolumn{3}{|c|}{ (b) } \\
\hline & $n$ & $n^{\prime}$ & $N$ & $10^{3} / v_{\text {m in }}$ & & & $n^{\prime}$ & $N$ & $10^{3} / v_{\text {min }}$ \\
\hline 24 & 3 & 24 & 9 & 44.1 & 40 & 8 & 45 & 11 & 40.4 \\
\hline & & & & & 42 & 8 & 42 & 11 & 40.3 \\
\hline 25 & 3 & 25 & 9 & 44.1 & 44 & 8 & 41 & 9 & 39. 7 \\
\hline 26 & 4 & 25 & 9 & 43.8 & 46 & 8 & 40 & 9 & 39.1 \\
\hline 27 & 5 & 27 & 9 & 43.8 & 48 & 8 & 39 & 9 & 38.4 \\
\hline 28 & 6 & 29 & 9 & 43.4 & & & & & \\
\hline 29 & 7 & 31 & 9 & 43.4 & $\begin{array}{l}50 \\
55\end{array}$ & 8 & 38 & 9 & 37.6 \\
\hline 30 & 8 & 33 & 11 & 42.9 & $\begin{array}{l}55 \\
60\end{array}$ & $\begin{array}{l}8 \\
8\end{array}$ & $\begin{array}{l}37 \\
36\end{array}$ & $\begin{array}{l}9 \\
9\end{array}$ & $\begin{array}{l}36.6 \\
35.9\end{array}$ \\
\hline 31 & 8 & 35 & 13 & 42.9 & 65 & 8 & 34 & 9 & 34.6 \\
\hline 32 & 8 & 38 & 13 & 42.5 & 70 & 8 & 33 & 7 & 34.0 \\
\hline 33 & 8 & 47 & 15 & 42.4 & & & & & \\
\hline 34 & 8 & 48 & 13 & 42.0 & 75 & 8 & 30 & 7 & 31.8 \\
\hline 35 & 8 & 48 & 11 & 42.0 & $\begin{array}{l}80 \\
85\end{array}$ & $\begin{array}{l}8 \\
8\end{array}$ & $\begin{array}{l}29 \\
28\end{array}$ & 7 & 30.8 \\
\hline 36 & 8 & 47 & 11 & 41.5 & 90 & 8 & 27 & 7 & $\begin{array}{l}29.8 \\
28.9\end{array}$ \\
\hline 37 & 8 & 47 & 11 & 41.5 & 95 & 8 & 26 & 5 & $\begin{array}{l}28.9 \\
28.1\end{array}$ \\
\hline 38 & 8 & 46 & 11 & 40.9 & & & & & \\
\hline 39 & 8 & 46 & 11 & 40.9 & 100 & 8 & 24 & 5 & 26.6 \\
\hline
\end{tabular}

s For $N=2$ and $0.001 \leq 1 / v \leq 0.007 \mathrm{~g} \mathrm{~mol} / \mathrm{cm}^{3}$

$\mathrm{b}$ To the highest experimental densities, $10^{3} / r_{\mathrm{min}}$

TAвLE 2. Derived and calculated values of $\mathrm{B}, \mathrm{cm}^{3} / \mathrm{g} \mathrm{mol}$

\begin{tabular}{|c|c|c|c|c|c|c|c|}
\hline \multirow{2}{*}{$T,{ }^{\circ} K$} & \multirow{2}{*}{ Derived } & \multicolumn{2}{|c|}{ Calculated } & \multirow{2}{*}{$T,{ }^{\circ} K$} & \multirow{2}{*}{ Derived } & \multicolumn{2}{|c|}{ Calculated } \\
\hline & & $(2 a)$ & $(2 \mathrm{~b})$ & & & $(2 \mathrm{a})$ & $(2 \mathrm{~b})$ \\
\hline $\begin{array}{l}15 \\
16 \\
17 \\
18 \\
19\end{array}$ & $\begin{array}{l}-204.2 \\
-172.9\end{array}$ & $\begin{array}{l}-219.4 \\
-200.8 \\
-184.7 \\
-170.6 \\
-158.2\end{array}$ & $\begin{array}{l}-222.3 \\
-202.8 \\
-186.1 \\
-171.5 \\
-158.7\end{array}$ & $\begin{array}{l}50 \\
55 \\
60 \\
65 \\
70\end{array}$ & $\begin{array}{l}-33.39 \\
-27.48 \\
-22.70 \\
-18.64 \\
-15.22\end{array}$ & $\begin{array}{l}-33.25 \\
-27.29 \\
-22.43 \\
-18.40 \\
-15.01\end{array}$ & $\begin{array}{l}-33.47 \\
-27.53 \\
-22.67 \\
-18.63 \\
-15.23\end{array}$ \\
\hline $\begin{array}{l}20 \\
21 \\
22 \\
23 \\
24\end{array}$ & $\begin{array}{l}-148.8 \\
-129.7 \\
-112.8\end{array}$ & $\begin{array}{l}-147.1 \\
-137.2 \\
-128.4 \\
-120.3 \\
-113.1\end{array}$ & $\begin{array}{l}-147.4 \\
-137.4 \\
-128.4 \\
-120.3 \\
-113.0\end{array}$ & $\begin{array}{l}75 \\
80 \\
85 \\
90 \\
95\end{array}$ & $\begin{array}{r}-12.42 \\
-9.88 \\
-7.63 \\
-5.66 \\
-3.99\end{array}$ & $\begin{array}{r}-12.13 \\
-9.65 \\
-7.50 \\
-5.61 \\
-3.95\end{array}$ & $\begin{array}{r}-12.32 \\
-9.82 \\
-7.63 \\
-5.72 \\
-4.02\end{array}$ \\
\hline $\begin{array}{l}25 \\
26 \\
27 \\
28 \\
29\end{array}$ & $\begin{array}{l}-106.2 \\
-100.3 \\
-94.80 \\
-89.66 \\
-85.03\end{array}$ & $\begin{array}{c}-106.5 \\
-100.4 \\
-94.88 \\
-89.78 \\
-85.08\end{array}$ & $\begin{array}{l}-106.3 \\
-100.3 \\
-94.74 \\
-89.65 \\
-84.96\end{array}$ & $\begin{array}{l}98.15 \\
100 \\
103.15 \\
113.15 \\
123.15\end{array}$ & $\begin{array}{r}-3.06 \\
-2.52 \\
-1.69 \\
+0.67 \\
2.63\end{array}$ & $\begin{array}{r}-2.99 \\
-2.47 \\
-1.62 \\
+0.73 \\
2.65\end{array}$ & $\begin{array}{r}-3.05 \\
-2.51 \\
-1.65 \\
+0.75 \\
2.73\end{array}$ \\
\hline $\begin{array}{l}30 \\
31 \\
32 \\
33 \\
34\end{array}$ & $\begin{array}{l}-80.73 \\
-76.75 \\
-72.99 \\
-69.53 \\
-66.22\end{array}$ & $\begin{array}{l}-80.72 \\
-76.68 \\
-72.93 \\
-69.43 \\
-66.16\end{array}$ & $\begin{array}{l}-80.62 \\
-76.60 \\
-72.86 \\
-69.39 \\
-66.14\end{array}$ & $\begin{array}{l}138.15 \\
153.15 \\
173.15 \\
198.15 \\
223.15\end{array}$ & $\begin{array}{r}5.01 \\
6.89 \\
8.84 \\
10.65 \\
11.98\end{array}$ & $\begin{array}{r}4.96 \\
6.76 \\
8.62 \\
10.37 \\
11.68\end{array}$ & $\begin{array}{r}5.09 \\
6.94 \\
8.85 \\
10.62 \\
11.93\end{array}$ \\
\hline $\begin{array}{l}35 \\
36 \\
37 \\
38 \\
39\end{array}$ & $\begin{array}{l}-63.17 \\
-60.26 \\
-57.54 \\
-54.99 \\
-52.60\end{array}$ & $\begin{array}{l}-63.09 \\
-60.22 \\
-57.53 \\
-54.99 \\
-52.60\end{array}$ & $\begin{array}{l}-63.10 \\
-60.25 \\
-57.58 \\
-55.06 \\
-52.69\end{array}$ & $\begin{array}{l}248.15 \\
273.15 \\
298.15 \\
323.15 \\
348.15\end{array}$ & $\begin{array}{l}12.97 \\
13.76 \\
14.38 \\
14.87 \\
15.27\end{array}$ & $\begin{array}{l}12.70 \\
13.51 \\
14.17 \\
14.71 \\
15.17\end{array}$ & $\begin{array}{l}12.94 \\
13.72 \\
14.34 \\
14.85 \\
15.25\end{array}$ \\
\hline $\begin{array}{l}40 \\
42 \\
44 \\
46 \\
48\end{array}$ & $\begin{array}{l}-50.32 \\
-46.19 \\
-42.50 \\
-39.18 \\
-36.17\end{array}$ & $\begin{array}{l}-50.34 \\
-46.19 \\
-42.46 \\
-39.09 \\
-36.03\end{array}$ & $\begin{array}{l}-50.45 \\
-46.33 \\
-42.62 \\
-39.28 \\
-36.24\end{array}$ & $\begin{array}{l}373.15 \\
398.15 \\
423.15\end{array}$ & $\begin{array}{l}15.60 \\
15.86 \\
16.08\end{array}$ & $\begin{array}{l}15.56 \\
15.90 \\
16.19\end{array}$ & $\begin{array}{l}15.59 \\
15.87 \\
16.10\end{array}$ \\
\hline
\end{tabular}

Uncertainty in $B$, estimated from eq (1) for low densities, is

$$
\delta B=\left[2 Z-1+C / v^{2}\right] \delta v-v Z \delta T / T
$$

where $Z \equiv P v / R T$, or approximately

$$
\delta B \approx v[\delta v / v-\delta T / T] .
$$

Experimental uncertainty in $v$ was estimated to be 0.2 percent at low densities [2]. Examination of the sensitivity of the shape of isotherms of $(P v-R T) v$ to errors in density, however, indicates a precision near 0.02 percent. This is illustrated by figure 1

\begin{tabular}{|c|c|c|c|c|c|}
\hline \multirow{2}{*}{$T,{ }^{\circ} \mathrm{K}$} & \multicolumn{2}{|c|}{ C. $\left(\mathrm{cm}^{3} / \mathrm{g} \mathrm{mol}\right)^{2}$} & \multirow{2}{*}{$T,{ }^{\circ} K$} & \multicolumn{2}{|c|}{ C. $\left(\mathrm{cm}^{3} / \mathrm{g} \mathrm{mol}\right)^{2}$} \\
\hline & Derived & Calc'd. & & Derived & Calc'd \\
\hline 20 & & -405 & 50 & 964 & 968 \\
\hline 21 & - & +218 & 55 & 889 & 893 \\
\hline 22 & . & 680 & 60 & 838 & 835 \\
\hline 23 & & 1018 & 65 & 785 & 789 \\
\hline 24 & 1207 & 1259 & 70 & 743 & 750 \\
\hline 25 & 1402 & 1425 & 75 & 726 & 718 \\
\hline $\begin{array}{l}26 \\
27\end{array}$ & $\begin{array}{l}1580 \\
1627\end{array}$ & $\begin{array}{l}1533 \\
1596\end{array}$ & $\begin{array}{l}80 \\
85\end{array}$ & $\begin{array}{l}694 \\
659\end{array}$ & $\begin{array}{l}690 \\
665\end{array}$ \\
\hline 28 & 1612 & 1625 & 90 & 636 & 643 \\
\hline 29 & 1615 & 1629 & 95 & 624 & 624 \\
\hline 30 & 1600 & 1614 & 98.15 & 530 & 613 \\
\hline 31 & 1585 & 1586 & 100 & 609 & 606 \\
\hline 32 & 1550 & 1549 & 103.15 & 560 & 596 \\
\hline 33 & 1516 & 1507 & 113.15 & 540 & 567 \\
\hline 34 & 1466 & 1463 & 123.15 & 560 & 542 \\
\hline 35 & 1426 & 1418 & 138.15 & 540 & 510 \\
\hline 36 & 1377 & 1373 & 153.15 & 522 & 483 \\
\hline 37 & 1331 & 1330 & 173.15 & 500 & 454 \\
\hline 38 & 1290 & 1290 & 198. 15 & 458 & 424 \\
\hline 39 & 1252 & 1251 & 223.15 & 437 & 399 \\
\hline 40 & 1209 & 1215 & 248.15 & 415 & 378 \\
\hline 42 & 1144 & 1151 & 273.15 & 404 & 360 \\
\hline 44 & 1091 & 1095 & 298.15 & 370 & 345 \\
\hline \multirow{5}{*}{$\begin{array}{l}40 \\
48\end{array}$} & 1046 & 1047 & 323.15 & 340 & 331 \\
\hline & 1005 & 1005 & 348.15 & 313 & 319 \\
\hline & & & & 303 & \\
\hline & & & 398.15 & 310 & 298 \\
\hline & & & 423.15 & 302 & 289 \\
\hline
\end{tabular}

TABle 3. Derived and calculated third virial coefficients

in which the upper curve is an experimental linear isotherm, and the lower curve shows the effect of an artificially introduced error of 0.263 percent in density [2]. As a further illustration figure 2 gives deviations of the data from the least-squared, truncated virial expression at $44{ }^{\circ} \mathbf{K}$ and compares these with the boundary for a deviation of \pm 0.02 percent in density. From such considerations, the precision of these lowest experimental densities appears to be within 0.03 percent. Since this applies to all isotherms, the corresponding error in $B$ should be roughly independent of temperature. For the lowest density, $v=1000 \mathrm{~cm}^{3} / \mathrm{g}$ mol; uncertainty in $B$ thus is estimated to be about $0.3 \mathrm{~cm}^{3} / \mathrm{g} \mathrm{mol}$. Systematic deviations in the temperature-dependence of $B$, on the other hand, may be sought in absolute deviations of the NBS temperature scale for platinum resistance. For $\delta T=0.02{ }^{\circ} \mathrm{K}, v=1000$ $\mathrm{cm}^{3} / \mathrm{g}$ mol, and $25^{\circ} \leq T \leq 100{ }^{\circ} \mathrm{K}$, the range of uncertainty is $0.8 \leq \delta B \leq 0.2 \mathrm{~cm}^{3} / \mathrm{g}$ mol.

Since $B$ is derived as the intercept of linear plots of $(P v / R T-1) v$ versus $1 / v$, it may be seen that all of the above arguments for precision apply equally to absolute errors in $v$ or in $T$. Absolute uncertainty in $B$ therefore is estimated to be in the range 1.1 $\mathrm{cm}^{3} / \mathrm{g} \mathrm{mol}$ at $25^{\circ} \mathrm{K}$ to $0.5 \mathrm{~cm}^{3} / \mathrm{g}$ mol at $100{ }^{\circ} \mathrm{K}$.

To the above virial coefficients for parahydrogen from 24 to $100^{\circ}$ in tables 2 and 3 have been added values for normal hydrogen at higher and lower temperatures in order to provide a more extensive set. Of the published values of virial coefficients for normal hydrogen $[4,8,9,10,11,12]$, values from Woolley, Scott, and Brickwedde [9] below $24{ }^{\circ} \mathrm{K}$ are included in table 2, while values from Michels, de Graaff, and Ten Seldam [10] at nonintegral temperatures above $98^{\circ} \mathrm{K}$ are given in tables 2 and 


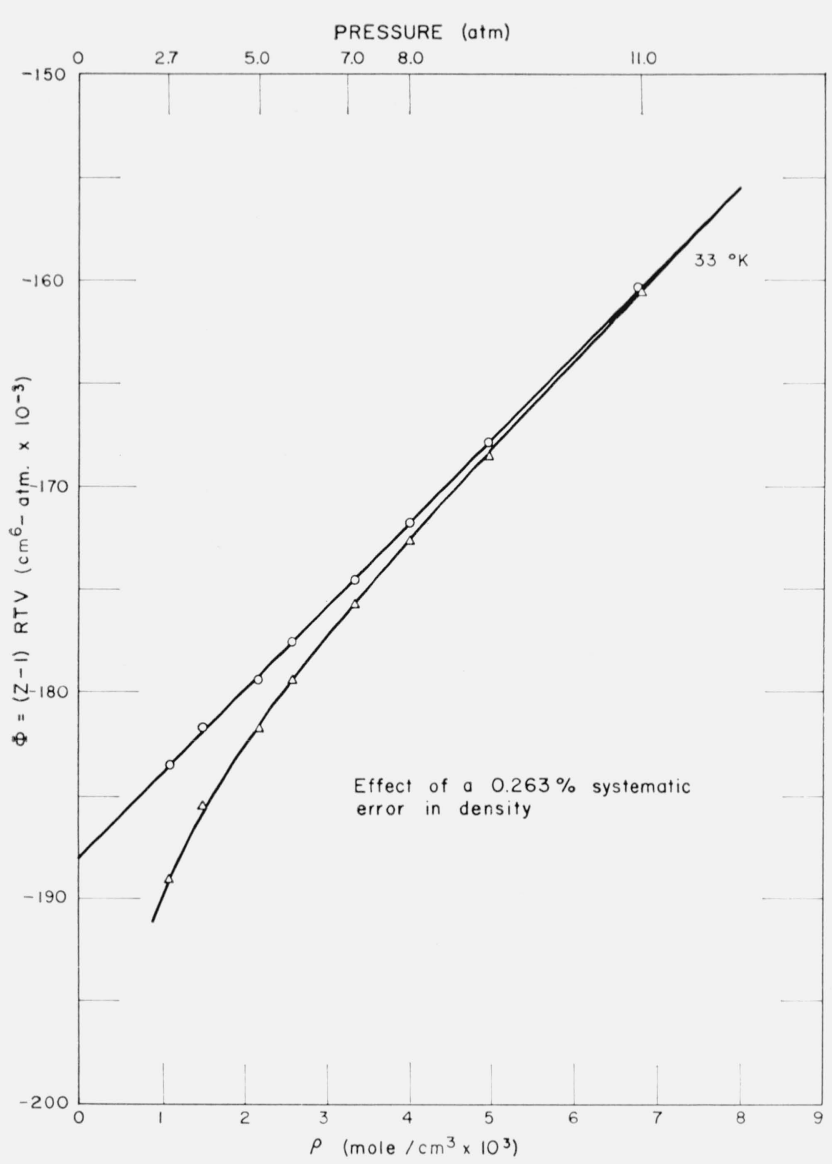

Figure 1. Effect of systematic error in density [2] upon the linear behavior of eq. (1), for the $33^{\circ} \mathrm{K}$ isotherm.

The notation is $Z \equiv P v / R T$. Circles: experimental linear isotherm. Triangles: same data with artifically introduced error of 0.263 percent.

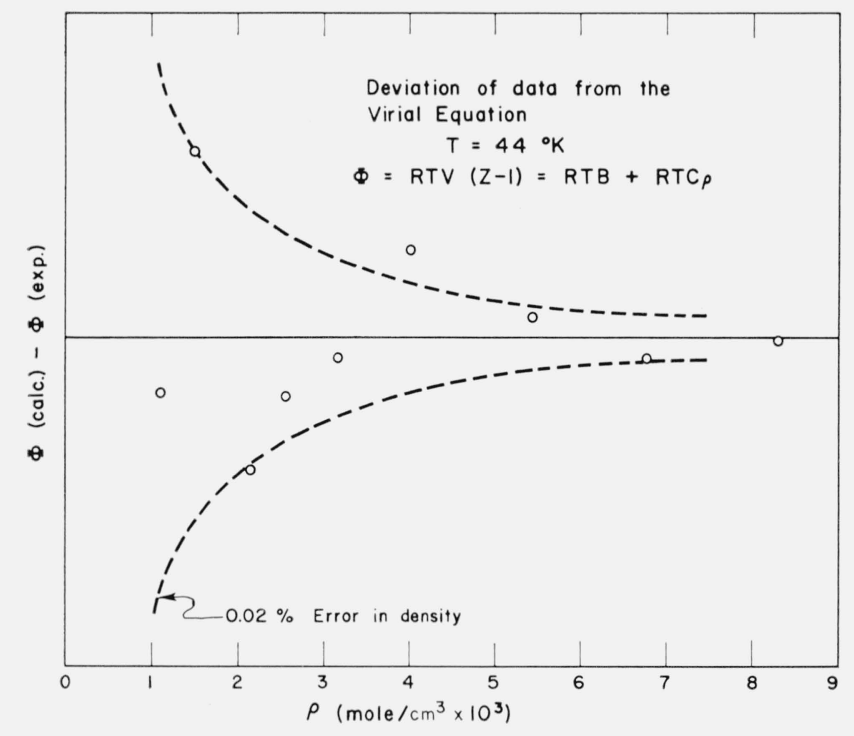

Figure 2. Deviations of data, $\Phi \equiv(\mathrm{Z}-1) \mathrm{RT}$, where $\mathrm{Z} \equiv$ $\mathrm{Pv} / \mathrm{RT}$, from eq. (1) at $44^{\circ} \mathrm{K}$.

Dashed lines correspond to \pm 0.02 percent systematic error in density.
3. Uncertainty of the data of Michels et al., was estimated by them to be $0.15 \mathrm{~cm}^{3} / \mathrm{g}$ mol in $B$, and about 15 percent in $C$. Excellent agreement of the independent data at $100{ }^{\circ} \mathrm{K}$ suggests that the virial coefficients of these hydrogen modifications may be indistinguishable at this and higher temperatures. Small differences have been detected at lower temperatures [13].

\section{Representation of Second Virial Coefficient}

Figure 3 presents the derived data of table 2 as a function of $T^{-5 / 4}$. The data for normal hydrogen at low temperatures are seen to deviate from the straight line extrapolated from the parahydrogen data, in agreement with the experimental comparison of the two modifications made by Beenakker et al. [13].

Systematic deviations persist with all analytical representations which have been investigated for the temperature-dependence of $B$. It therefore does not appear possible to select a form which is best for all purposes from among the following two, which utilize two and four constants, respectively, with notation $x \equiv T_{0} / T$ :

$$
\begin{aligned}
B & =B_{0}\left[1-x^{5 / 4}\right], & T_{0} & =109.83^{\circ} \mathrm{K}, \\
B_{0} & =19.866 \mathrm{~cm}^{3} / \mathrm{g} \mathrm{mol}, & \Delta & =0.125 \mathrm{~cm}^{3} / \mathrm{g} \mathrm{mol} .
\end{aligned}
$$

$$
\begin{array}{rlrl}
B & =\sum_{i=1}^{4} B_{i} x^{(2 i-1) / 4}, & & T_{0}=109.781^{\circ} \mathrm{K}, \\
B_{1} & =+42.464, & & B_{2}=-37.1172, \\
B_{3} & =-2.2982, & B_{4}=-3.0484, \\
\Delta & =0.066 \mathrm{~cm}^{3} / \mathrm{g} \mathrm{mol} . &
\end{array}
$$

Mean deviations, given for each equation above, are defined as

$$
\Delta \equiv(n-N)^{-1} \sum^{n}\left|B-B_{\text {cale }}\right|,
$$

wherein $n=49$ is the number of datum pairs, and $N$ is the number of constants in the equation. Calculated results from these equations are given in table 2 , and the individual deviations are plotted in figure 4 .

The form of (2a) is that used by Keesom for helium [14], the constant high-temperature limit corresponding to the rigid-sphere model for molecular interaction [5]. The value of $B_{0}$ in (2a) is comparable with the volume $22.65 \mathrm{~cm}^{3} / \mathrm{g}$ mol of solid normal hydrogen at $4.2^{\circ} \mathrm{K}$ [9]. The rather good fit provided by this simple equation is indicated by figure 3. Equation (2b) consists of the leading terms of an expansion derived from the LennardJones potential [5]. Appendix, table II, gives coefficients for that expansion with increasing number of terms. (The form of the expansion given in 


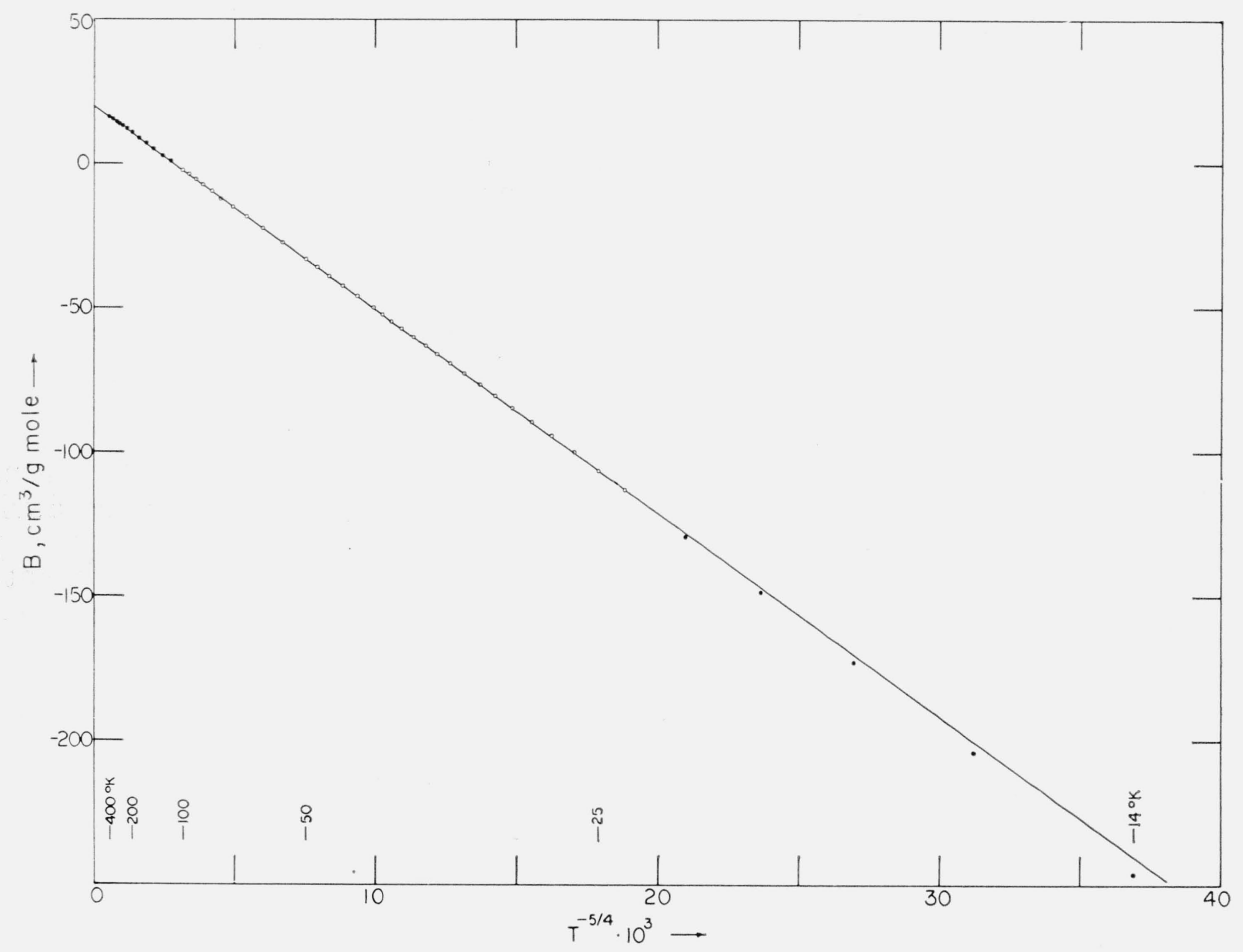

Figure 3. Second virial coefficient, B, versus $\mathrm{T}^{-5 / 4}$. $[10]$

Open circles are for parahydrogen. Filled circles for normal hydrogen below $24^{\circ} \mathrm{K}$ are from [9] and above $100{ }^{\circ} \mathrm{K}$ from

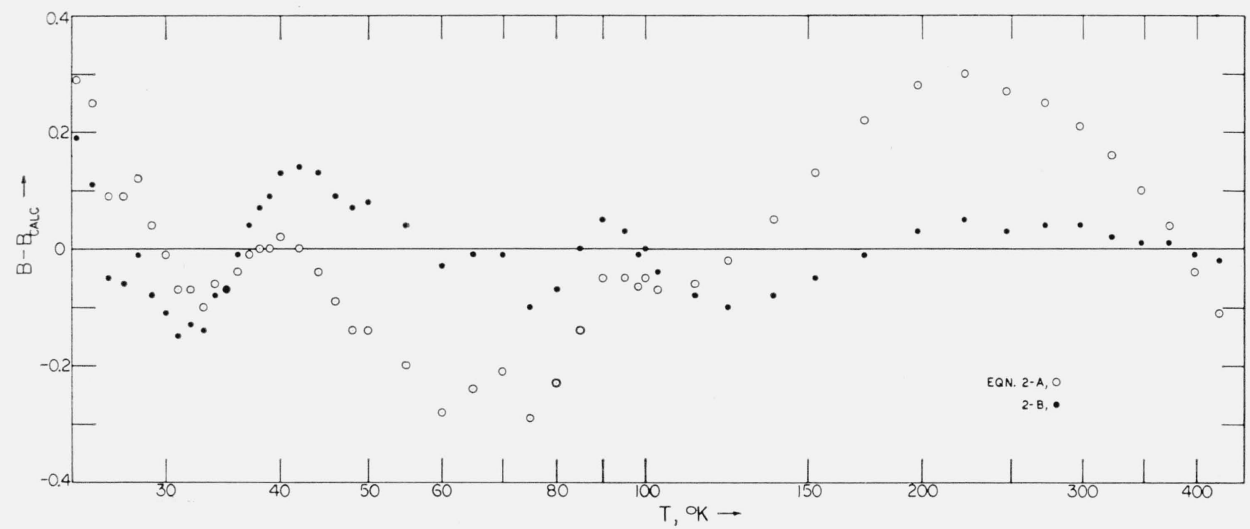

Figure 4. Deviations of second virial coefficient, B, in $\mathrm{cm}^{3} / \mathrm{g} \mathrm{mol}$, from eq (2a), open circles and from (2b), filled circles.

the appendix does not include the root, $T_{0}$.) $\mathrm{It}$ is seen that four terms give an acceptable representation. Whereas use of additional terms improves the fit, the similarity in form of the two sets of deviations in figure 4 suggests the presence of systematic experimental errors. If such errors are present, it is doubtful that use of higher terms would be justi- fied. The form of the deviations in figure 4 having been found also with analytical representations of $B$ other than polynomials, it is improbable that they arise from the selected polynomial forms of (2a) and (2b). It appears equally improbable that they arise entirely from deviations of the NBS temperature scale used. 


\section{Representation of Third Virial Coefficient}

The Lennard-Jones potential yields an expansion in powers of $T^{-1 / 2}$ [5]. From this key, eq (3) was evolved, using notation $x \equiv T_{0} / T$,

$$
\begin{array}{cl}
C=C_{0} x^{1 / 2}\left[1+c x^{3}\right]\left[1-\exp \left(1-x^{-3}\right)\right], \\
T_{0}=20.615^{\circ} \mathrm{K}, & C_{0}=1310.5\left(\mathrm{~cm}^{3} / \mathrm{g} \mathrm{mol}\right)^{2}, \\
c=2.1486, & \Delta=17.4\left(\mathrm{~cm}^{3} / \mathrm{g} \mathrm{mol}\right)^{2} .
\end{array}
$$

It represents the third virial coefficient within the apparent precision of the data. The last factor on the right of (3) differs significantly from unity only at temperatures below $40^{\circ} \mathrm{K}$. Calculated values of $C$ are given in table 3 .

The series

$$
C=\sum_{i=1}^{n} C_{i} T^{-i / 2}
$$

requires at least six terms to give a better representation than eq (3). The alternating series obtained by least-squares, however, are highly divergent; for example, the fifth term for $N=6$ exceeds the value of $C$ by factor 240 at $24^{\circ} \mathrm{K}$.

\section{Note on Two-Term Representations}

The behavior of plots of $y \equiv B$ or $C$ as functions of $x \equiv T_{0} / T$ suggests an empirical relation of the form

$$
y / y_{0}=x^{\mu}-x^{\nu}
$$

with constants $\mu<\nu$. The limitations of (4) having been examined in obtaining (2) and (3) above, it is reasonable next to examine the relation

$$
y / y_{0}=\exp \left(k x^{\mu}\right)-\exp \left(k x^{\nu}\right) .
$$

Since the five parameters in (4a) must be found tediously by trial, the exploration has been discontinued with preliminary results in the following table. It is concluded that (4a) may be sufficiently flexible to offer promise of accurate representations of both $B$ and $C$.

\begin{tabular}{|c|c|c|c|c|c|c|c|}
\hline$y$ & $\mu$ & $\nu$ & $k$ & $T_{0}$ & $y_{0}$ & $n$ & $\Delta$ \\
\hline$B$ & $1 / 4$ & $1 / 2$ & 0.6 & 110.9 & 92.18 & 49 & 0.20 \\
\hline$C$ & $1 / 2$ & 1 & 4 & 20 & 135 & 32 & 55 \\
\hline
\end{tabular}

$$
\Delta \equiv(n-3)^{-1} \sum^{n}\left|y-y_{\text {calc }}\right| .
$$

Robert J. Corruccini and Paul F. Wacker of this

\begin{tabular}{|c|c|c|c|c|c|}
\hline$T,{ }^{\circ} K$ & $B, \mathrm{~cm}^{3} / \mathrm{g} \mathrm{mol}$ & $C, \mathrm{~cm}^{3} / \mathrm{g} \mathrm{mol}^{2}$ & $T,{ }^{\circ} K$ & $B, \mathrm{~cm}^{3} / \mathrm{g} \mathrm{mol}$ & $C, \mathrm{~cm}^{3} / \mathrm{g} \mathrm{mol}^{2}$ \\
\hline 24 & -115.3 & 5601 & $\begin{array}{l}40 \\
42\end{array}$ & $\begin{array}{l}-50.18 \\
-46.02\end{array}$ & $\begin{array}{r}1027 \\
919\end{array}$ \\
\hline 25 & -106.5 & 1952 & 44 & -42.54 & $\begin{array}{l}3134 \\
1134\end{array}$ \\
\hline $\begin{array}{l}26 \\
27\end{array}$ & $\begin{array}{l}-101.1 \\
-95.01\end{array}$ & $\begin{array}{l}2736 \\
2032\end{array}$ & $\begin{array}{l}46 \\
48\end{array}$ & $\begin{array}{l}-39.25 \\
-36.28\end{array}$ & $\begin{array}{l}1108 \\
1103\end{array}$ \\
\hline 28 & -90.36 & 2624 & & & \\
\hline 29 & -85.72 & 2561 & $\begin{array}{l}50 \\
55\end{array}$ & $\begin{array}{l}-33.49 \\
-27.67\end{array}$ & $\begin{array}{l}1050 \\
1068\end{array}$ \\
\hline 30 & -80.96 & 1725 & 60 & -22.93 & 1057 \\
\hline & & 2180 & 65 & -18.77 & 906 \\
\hline $\begin{array}{l}32 \\
33\end{array}$ & $\begin{array}{l}-73.69 \\
-69.14\end{array}$ & $\begin{array}{r}2642 \\
554\end{array}$ & 70 & -15.30 & 809 \\
\hline 34 & -66.27 & $\begin{array}{r}504 \\
1549\end{array}$ & 75 & -12.57 & 854 \\
\hline 35 & -63.29 & 1537 & $\begin{array}{l}80 \\
85\end{array}$ & $\begin{array}{l}-9.96 \\
-7.58\end{array}$ & 615 \\
\hline 36 & -60.30 & 1402 & 90 & -5.57 & 559 \\
\hline 37 & -57.51 & 1280 & 95 & -4.00 & 637 \\
\hline 38 & -55.04 & 1335 & & & \\
\hline 39 & -52.66 & 1321 & 100 & -2.52 & 620 \\
\hline
\end{tabular}
laboratory made numerous suggestions for improving the manuscript, for which the authors are most appreciative. This work was supported by the $\mathrm{N}$ ational Aeronautics and Space Administration.

\section{Appendix}

TABLE I. Virial coefficients from extended isotherms of eq (1)

TABle II. Polynomial coefficients in Lennard-Jones expansion for second virial coefficient

$$
B=\sum_{i=1}^{N} b_{i} T^{-(2 i-1) / 4},\left(\mathrm{~cm}^{3} / \mathrm{g} \mathrm{mol}\right)
$$

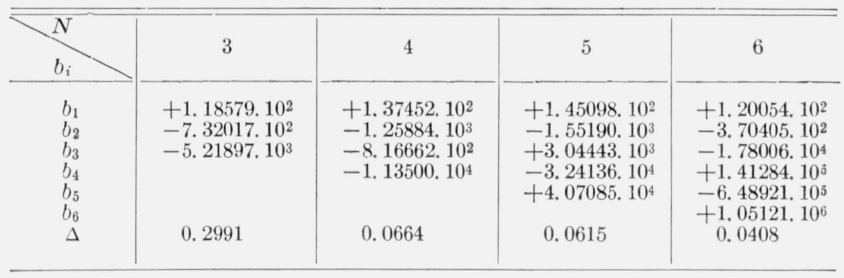

\section{References}

[1] R. D. Goodwin, D. E. Diller, H. M. Roder, and L. A. Weber, Pressure-density-temperature relations of fluid parahydrogen from 15 to $100{ }^{\circ} \mathrm{K}$ at pressures to 350 atm, J. Res. NBS $69 \mathbf{A}$ (Phys. and Chem.) No. 2, 173 (1963).

[2] R. D. Goodwin, Apparatus for determination of pressure-density-temperature relations and specific heats of hydrogen to $350 \mathrm{~atm}$. at temperatures above 14 ${ }^{\circ} \mathrm{K}$, J. Res. NBS 65C (Eng. and Instr.) No. 4, 231 (1961).

[3] H. M. Roder, L. A. Weber, and R. D. Goodwin, Thermodynamic and related properties of parahydrogen from the triple point to $100{ }^{\circ} \mathrm{K}$ at pressures to $340 \mathrm{~atm}$ (to be published).

[4] L. Holborn and J. Otto, On the isotherms of some gases between +400 and $-183^{\circ}$, Z. Physik 33, 1(1925); 38, 359 (1926).

[5] J. O. Hirschfelder, C. F. Curtiss, and R. B. Bird, Molecular theory of gases and liquids (John Wiley and Sons Inc., New York, N.Y., 1954).

[6] H. M. Roder, D. E. Diller, L. A. Weber, and R. D. Goodwin, The orthobaric densities of parahydrogen, derived heats of vaporization and critical constants, Cryogenies 3, 16 (1963)

[7] A. Michels, J. C. Abels, C. A. Ten Seldam, and W. de Graaff, Polynomial representation of experimental data; application to virial coefficients of gases, Physica 26, 381 (1960).

[8] H. L. Johnston, I. I. Bezman, and C. B. Hood, JouleThomson effects in hydrogen at liquid air and room temperatures, J. Am. Chem. Soc. 68, 2367 (1946) 
[9] H. W. Woolley, R. B. Scott, and F. G. Brickwedde, Compilation of thermal properties of hydrogen in its various isotopic and ortho-para modifications, J. Res. NBS 41, 379 (1948) RP1932.

[10] A. Michels, W. de Graaff, and C. A. Ten Seldam, Virial coefficients of hydrogen and deuterium at temperatures between $-175^{\circ} \mathrm{C}$ and $+150^{\circ} \mathrm{C}$. Conclusions from the second virial coefficient with regard to the intermolecular potential, Physica 26, 393 (1960).

[11] Roseann Piser, The virial coefficients of hydrogen, Thesis, Dept. of Chem., Brooklyn College (Jan. 1960).
[12] H. F. P. Knaap, M. Knoester, C. M. Knobler, and J. J. M. Beenakker, The second virial coefficients of the hydrogen isotopes between 20 and $70{ }^{\circ} \mathrm{K}$, Physica 28, 21 (1962).

[13] J. J. M. Beenakker, F. H. Varekamp, and H. F. P. Knaap, The second virial coefficient of ortho and para hydrogen at liquid hydrogen temperatures, Physica 26, 43 (1960)

[14] W. H. Keesom, Helium (Elsevier Publ. Co., (1942).

(Paper 68A1-260) 